\title{
CILIATE PROTOZOA POLYPLASTRON MULTIVESICULATUM FROM THE RUMEN OF INDIAN GOAT CAPRA HIRCUS (L.)
}

\author{
P.K. Sanghai \\ Dept. of Zoology, Shivaji A.C. \& Sci. College, Kannad-431 103 \\ Dist. Aurangabad (M.S.) India. \\ Email: prashantksanghai@gmail.com, prashant.sanghai@rediffmail.com
}

\begin{abstract}
An investigation has been made to observe the morphology of rumen ciliate protozoa. A total 458 rumen fluid samples of the Indian goat Capra hircus were collected for one year. The study reveals that occurrence of Polyplastron multivesiculatum (Dogiel 1925). The body dimensions and variations of characters recorded from the specimens taken $(n=20)$ at random from different slides and compared with earlier findings and critical comments were made on their specific identity. The presence of P.multivesiculatum in the rumen of goat is the new record in Maharashtra (India)
\end{abstract}

KEYWORDS: Rumen, Goat, Protozoa, Ciliates, Polyplastron

\section{INTRODUCTION}

Polyplastron multivesiculatum is an entodiniomorphid ciliated protozoa, belonging to the family Ophryoscolecidae, (Order: Entodiniomorphida), was first reported by Dogiel $^{8}$ from the rumen of domestic cattle in U.S.S.R. After that, it had been described from different geographical parts all over the world and several hosts. Dehority ${ }^{5}$, from Alaska, Ogimoto \& Imai ${ }^{23}$ from Japan, Gocman et $a l^{10}$ from Turkey, Talu ${ }^{28}$, Rasteldgi S. \& Gocman B. ${ }^{24}$ from the rumen of Goat in Turkey. The study of rumen protozoan populations in different areas provides information about the geographical distribution of ciliates the physiology and feeding habits of hosts and the specificity and phylogeny of individual species (Dehority ${ }^{5}$; Ito et $a l^{14}$; Gocman \& Gurelli ${ }^{9}$ ). Becker and Talbott ${ }^{2}$ studied in American cattle, Clarke ${ }^{3}$ studied in New Zealand domestic cattle, Hsiung ${ }^{12}$ studied in Chinese cattle. However, very few morphological studies have been done on the ciliate fauna found in the rumen of Indian goat. Kofoid and Maclennan ${ }^{15,16,17}$ studied in different ruminants of India and Ceylon, Banerjee ${ }^{1}$ studied on rumen ciliates of cow, Buffalo and sheep, in India, Dasgupta, M. ${ }^{4}$ observed ciliates in the rumen of Indian goat, Mathur, C.S. ${ }^{19}$ studied the occurrence of ciliates in domesticated animals, Misra et $a l^{20}$ studied protozoan fauna of Indian cattle, Mukherjee \& Sinha ${ }^{21.22}$ studied ciliate protozoa from black Bengal goats, Kulkarni ${ }^{18}$ observed Entodiniid ciliates from cattle, Sanghai ${ }^{25}$, studied from the rumen of goat, Sanghai \& Kshirsagar ${ }^{26,27}$ observed ciliates from cattle. The comparative studies of the rumen ciliate populations of various hosts in different regions should provide information on phylogenetic relationships between the rumen ciliates and the host ruminants 
(Ogimoto \& Imai ${ }^{23}$, Gocman et al ${ }^{11}$ ). The present study reveals that occurrence of Polyplastron multivesiculatum (Dogiel ${ }^{5}$ ) and the information is compared with data from previous reports conducted in other geographical areas. .The study reports first time in Maharashatra (India) the presence of P.multivesiculatum in the rumen of goat.

\section{MATERIALS AND METHODS}

During the present study rumen fluid samples were collected from 458 adult Indian goats Capra hircus slaughtered at abattoirs of Kannad, Dist. Aurangabad of Maharashatra State (India). After the removal of the stomach the rumen was slit open and $10-15 \mathrm{ml}$ of rumen fluid was collected in a glass vial then the immediately the glass vial was closed airtight and brought to the laboratory. It was centrifuged and preserved by adding 1:1 glycerine alcohol solution. To determine the intensity of the ciliates live specimen were examined under the microscope by taking drop of fluid on a clean glass slide.

The permanent slides of the sample were made in duplicate stained by wet Tungstophosphoric Hematoxylin stain. Identification of genera and species of rumen ciliates were based on description published by earlier workers $\left(\right.$ Dehority ${ }^{6}$ ). All the measures of the ciliates were based on a study of 20 specimens $(n=20)$ with an ocular micrometer.

\section{Description of the species: - (Fig. 1)}

The body of this species is large, heavy oval in shape. The adoral ciliary zone is relatively large comprises mouth. It is inclined ventrally at an angle of $25-30^{\circ}$. The left ciliary zone is comparatively short than the adoral ciliary zone. The operculum is relatively large, broad, extends anteriorly beyond the oral area. The body surfaces are smooth, dorsally it is convex than the ventral surface, and ventral surface is slightly concave especially behind the oral area and just anterior to the anus. The greatest diameter measured in the middle of the body. The posterior end is smooth rounded without any caudal lobe or spine.

The oesophagus is narrow tubular, extends posterior into anterior third of the endoplasmic sack. The endoplasmic sack is relatively large occupies greater part of the body. The ectoplasm is thicker than in most of the genera, well marked by distinct boundary layer. The rectum is large, tubular structure found at the posteroventral end of the body beneath the right side of the body. The rectum opens through a narrow slit like anus extending from middle of the posterior end to the right side.

The macronucleus is an elongate, straight, rod shape body. It founds slightly to the right of the mid-line and shows deep indentation at dorsal side where the small ellipsoidal micronucleus is situated. The anterior end of macronucleus thicker smoothly rounded. The posterior end is narrow, blunt ended. There are four contractile vacuoles situated at usual position along the left dorsal side of the macronucleus, one near the anterior end of 


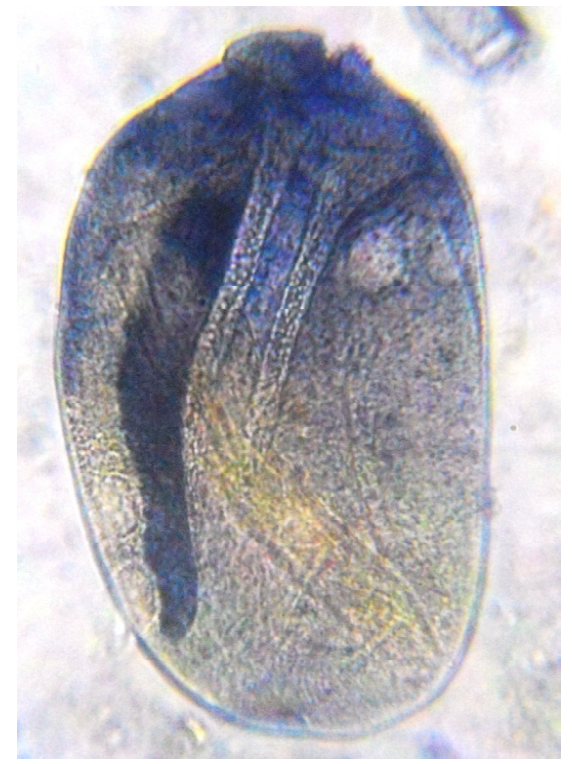

Fig. 1: Polyplastron multivesiculatum

the macronucleus, one at the level of micronucleus, one at the posterior one-third region of the macronucleus and one near the posterior tip the macronucleus. In addition to that two vacuoles lie under the dorsal surface and near the macronucleus. Two vacuoles lie near the middle of the right side, one between the skeletal plates and one just below the ventral plate. One more vacuole present under the ventral surface behind the oral region.

The presence of five skeletal plates is the most differentiating taxonomic feature of this ciliate; two skeletal plates lie beneath the right surface are similar in position and form to those in Metadinium and Elytroplastron. Dogiel ${ }^{7}$ found some specimens in which the right plates are fused partly or completely. The skeletal complex on the left side of polyplastron is composed of three plates connected by narrow bars. They extend diagonally from the edge of the adoral ciliary zone across the middle of the body. The first right dorsal skeletal plate made up of 6-7 rows of prisms. The second right dorsal skeletal plate is slightly narrower than the first. The third plate found beneath the left surface composed of 4-5 rows of longitudinal prisms. It extends from operculum diagonally across the left side. The two ventral plates, extends from the anterior end of the median plate, one going to the anterior end of each lateral plate, and another only a short distance posteriorly from the ventral edge of the oral zone. Skeletal plates beneath the left surface are found in only one other genus, Elytroplastron. The body dimensions and other measurements of Polytroplastron multivesiculatum are given in table 1.

\section{RESULTS AND DISCUSSION}

Dogiel and Fedorowa ${ }^{8}$ firstly described Polyplastron multivesiculatum from the rumen of domestic cattle in U.S.S.R. Thereafter many workers described this species from different localities of the world and various hosts Dehority ${ }^{5}$ studied in the rumen of Reindeer, from Alaska, Imai S. \& K. Tsunoda ${ }^{13}$ from the rumen of sheep in Japan, Ogimoto K. \& S. Imai ${ }^{23}$ from Japan, Talu $^{28}$ From KKTC, Gocman B. ${ }^{10}$ from Turky, Rasteldgi S. \& Gocman B. ${ }^{24}$ from the rumen of goat in Turky. A comparison of the dimensions of the species described here and those given by earlier workers are given in table 2 . 
The table indicates that the species described here is larger in body length, width than the length $\&$ width given by all the workers except the dimensions given by Gocman $\mathrm{B}^{10}$. The average $\mathrm{L} / \mathrm{W}$ ratio is slightly similar to the $\mathrm{L} / \mathrm{W}$ ratio described by Imai $\&$ Tsunoda ${ }^{13}$ and Dehority ${ }^{5}$.

Table 1: The body dimensions and other measurements of Polyplastron multivesiculatum are as below. All measurements are in microns. $(\mathrm{n}=20)$

\begin{tabular}{|l|l|c|c|c|}
\hline Sr.No. & Parameters & Minimum & Maximum & Average \\
& Body & & & \\
& Length & 138.15 & 245.60 & 188.03 \\
& Width & 95.17 & 162.71 & 118.66 \\
$\mathbf{2}$ & L/W Ratio & 1.26 & 1.71 & 1.58 \\
& Macronucleus & & & \\
& Length & 76.75 & 168.85 & 110.90 \\
& \% Length to the Body & 55.55 & 69.96 & 58.98 \\
& Diam. Ant. End. & 12.28 & 30.70 & 18.11 \\
$\mathbf{3}$ & Diam. Post. End & 6.14 & 15.35 & 7.22 \\
$\mathbf{5}$ & Micronucleus & 6.14 & 16.89 & 9.14 \\
& Adoral ciliary zone (Mouth) & 19.96 & 30.70 & 29.04 \\
\hline
\end{tabular}

Table 2: Comparative body dimensions of Polyplastron multivesiculatum

\begin{tabular}{|l|c|c|c|c|c|c|c|c|}
\hline Parameters & \multicolumn{9}{|c|}{ Authors } \\
\cline { 2 - 9 } & $\begin{array}{c}\text { Dogil \& } \\
\text { Fedorowa } \\
(1925)\end{array}$ & $\begin{array}{c}\text { Imai S. \& } \\
\text { Tsunoda K. } \\
(1972)\end{array}$ & $\begin{array}{c}\text { Dehority } \\
(1974)\end{array}$ & $\begin{array}{c}\text { K.Ogimoto } \\
\text { \& S. Imai } \\
(1981)\end{array}$ & $\begin{array}{c}\text { Gocman B. } \\
(1999)\end{array}$ & $\begin{array}{c}\text { Talu } \\
(1999)\end{array}$ & $\begin{array}{c}\text { S. Rasteldgi } \\
\text { \& Gocman } \\
\text { B. (2003) }\end{array}$ & $\begin{array}{c}\text { Present } \\
\text { Study }\end{array}$ \\
\hline Length & $\begin{array}{c}120-190 \\
(161)\end{array}$ & $\begin{array}{c}122-200 \\
(165)\end{array}$ & $\begin{array}{c}110-210 \\
(156)\end{array}$ & $122-210$ & $\begin{array}{c}177-247 \\
(209)\end{array}$ & $\begin{array}{c}133-205 \\
(172)\end{array}$ & $\begin{array}{c}114.2-179 \\
(150.28)\end{array}$ & $\begin{array}{c}138.15-245.60 \\
(188.03)\end{array}$ \\
\hline Width & $\begin{array}{c}78-140 \\
(95)\end{array}$ & $\begin{array}{c}97-130 \\
(112)\end{array}$ & $\begin{array}{c}78-142 \\
(103)\end{array}$ & $97-130$ & $\begin{array}{c}106-187 \\
(144)\end{array}$ & $\begin{array}{c}74-123 \\
(97)\end{array}$ & $\begin{array}{c}70-121 \\
(88)\end{array}$ & $\begin{array}{c}95.17-162.71 \\
(118.66)\end{array}$ \\
\hline L/W ratio & 1.7 & 1.5 & 1.51 & & 1.46 & 1.77 & $\begin{array}{c}1.37-2.11 \\
(1.70)\end{array}$ & $\begin{array}{c}1.26-1.71 \\
(1.58)\end{array}$ \\
\hline
\end{tabular}

ACKNOWLEDGEMENTS:

The author would like to thanks to
University Grants Commission (WRO) Pune providing research grant (No.47-583/08 
WRO) for this study and Principal, Shivaji A.C. \& Sci. College, Kannad, Dist. Aurangabad for providing laboratory and Library facilities.

\section{REFERENCES}

1. Banerjee, A.K., 1955. Studies on parasitic ciliates from Indian ruminants. Proc. Zool. Soc., 8(2):87-100.

2. Becker, E.R. and M. Talbott, 1927. The protozoan fauna of the rumen and reticulum of American cattle. Iowa State Coll. Jour. Sci., 1(3):345-365.

3. Clarke, R.T.J., 1964. Ciliates of the rumen of domestic cattle (Bos taurus) New Zeal. J. AGR Res., 7(3):248-257.

4. Das Gupta, M., 1935. Preliminary observations on the protozoan fauna of the rumen of the Indian goat Capra hircus Linn. Arch. Protistenk., 85(2):153-172.

5. Dehority, B.A., 1974. Rumen ciliate fauna of Alaskan Moose (Alces americana), MuskOx (Ovibos moschotus) and Dall Mountain Sheep (Ovis dalli). J. Protozool., 21(1):2632.

6. Dehority, B.A., 1993. Laboratory manual for classification and morphology of rumen ciliate protozoa. CRC. Press. INC, pp. 1-120.

7. Dogiel, V.A., 1927. Monographie der familie Ophryoscolecidae. Arch. Protistenk,.59:1288.

8. Dogiel, V.A., T. Fedorowa, 1925. Uber den Bau die Funktion des inneren Skeletts der Ophryoscoleciden. Zool. Anz., 62:97-107.

9. Gocman, B., G. Gurelli, 2009. The occurrence of the rumen ciliate Entodinium constrictum Dehority, $1974 \quad$ (Entodiniidae, Entodiniomorphida) from domestic sheep (Ovis ammon aries L.) in Northern Cyprus. North-Western J. Zool., 5:301-306.

10. Gocman, B., S. Torun, N. Oktem, 1999. Turkiye Evcil Koyun (Ovis ammon aries) larnin iskembe Siliyat (Protozooa : Ciliophora)
Faunasi Hakkinda Bir on Calisma: II Familya Ophryoscolecidae (Entodiniomorphida), Doga-Tr. Of Zoology, 23:(Eksayi 2):473-490

11. Gocman, B., S. Rastgeldi, A. Karaoglu and H. Askan, 2005. Rumen ciliated protozoa of the Turkish domestic goats (Capra hircus L.). Zootaxa, 1091:53-64.

12. Hsiung, T.S., 1932. A general survey of the protozoan fauna of the rumen of the Chinese cattle. Bull. Fan. Mem. Inst. Biol. Vol. III., 87-107.

13. Imai, S. \& K. Tsunoda, 1972. Scanning Electron Microscopic observations on the surface structures of ciliated protozoa in sheep rumen. Nat. Inst. Anim. Hlth. Quart., 12: 74-88.

14. Ito, A., S. Imai \& K. Ogimoto, 1994. Rumen ciliate composition and diversity of Japanese beef black cattle in comparison with those of Holstein-Friesian cattle. J. Vet. Med. Sci., 56:707-714.

15. Kofoid, C.A. \& R.F. Maclennan, 1930. Ciliates from Bos indicus the genus Entodinium Stein. Univ. Calif. Publ. Zool., 33(22):471-544.

16. Kofoid, C.A. \& R.F. Maclennan, 1932. Ciliates from Bos indicus II A revision of Diplodinium Schuberg. Univ. Calif. Publ. Zool., 37(5):53-152.

17. Kofoid, C.A. \& R.F. Maclennan, 1933. Ciliates from Bos indicus Epidinium Crawley. Univ.Calif. Publ. Zool., 39(11):1-34.

18. Kulkarni, S.A., 2001. Studies on rumen ciliates of cattle. $P h$. $D$ thesis SRTMU, Nanded, MS, India.

19. Mathur, C.S., 1963. Preliminary observations on the occurrence of some prominent forms of protozoa found in the rumen contents of domesticated animals. Indian Vet. J., 40(9): 551-553.

20. Misra, S.K., P.K. Das \& G.P. Mohanty, 1972. The protozoan fauna of the rumen and reticulum of Indian cattle. Indian Vet. J., 49: 463-469.

21. Mukherjee, G.S. \& P.K. Sinha, 1989. Seasonal 
variation of rumen protozoa in black Bengal goats. Indian J. Anim. Hlth., 28(2):153-154.

22. Mukherjee, G.S. \& P.K. Sinha, 1990. Incidence of rumen protozoa in black Bengal goats. Indian J. Anim. Hlth., 29(1):73-75.

23. Ogimoto, K. \& S. Imai, 1981. Atlas of rumen microbiology. Japan Sci. Soci. Press. (Tokyo), pp. 1-232.

24. Rastgeldi, S. \& B. Gocman, 2003. Polyplastron multivesiculatum in the rumen of domesticated goats. (Capra hircus L.) from Turkey Turkiye Parazitolji Dergisi, 27 (1):7174.

25. Sanghai, P.K., 2016. Study on the occurrence of the rumen ciliate Diplodinium sphericulatum from the rumen of Indian goat Capra hircus) CIBTech Journal of Microbiology, 5(4):1216.
26. Sanghai, P.K. \& H.S. Kshirsagr, 2010. Study on the occurrence of the rumen ciliate Diplodinium mahidoli (Imai \& Ogimoto, 1983) with one forma and Diplodinium mahidoli $\mathrm{F}$. bispinosum from cattle (Bos indicus) in India J. Adv. Zool., 31(1):45-49.

27. Sanghai, P.K. \& H.S. Kshirsagar, 2015. The occurrence of the rumen ciliate Enoplastron triloricatum (Dogiel 1925) from the rumen of Bos indicus in India. International Journal of Pure and Applied Zoology, 3(2):176-180.

28. Talu, G.H., 1999. Kuzey Kibris Turk Cumhuriyeti Evcil Kpyunlarnum (Ovis ammon aries) Ophryscolecid (Entodiniomorphida) iskembe Siliyat Faunast, Yuksek Lisans Tezi, E.U.Fen Bil. Enst., Izmir 